\title{
Spatial distribution modelling of Culicoides (Diptera: Ceratopogonidae) biting midges, potential vectors of African horse sickness and bluetongue viruses in Senegal
}

Maryam Diarra ${ }^{1,2,3^{*}}$, Moussa Fall ${ }^{1}$, Assane Gueye Fall ${ }^{1}$, Aliou Diop², Renaud Lancelot ${ }^{4,5}$, Momar Talla Seck ${ }^{1}$, Ignace Rakotoarivony ${ }^{4,5}$, Xavier Allène ${ }^{4,5}$, Jérémy Bouyer ${ }^{1,4,5}$ and Hélène Guis , $^{4,5,7,8}$

\begin{abstract}
Background: In Senegal, the last epidemic of African horse sickness (AHS) occurred in 2007. The western part of the country (the Niayes area) concentrates modern farms with exotic horses of high value and was highly affected during the 2007 outbreak that has started in the area. Several studies were initiated in the Niayes area in order to better characterize Culicoides diversity, ecology and the impact of environmental and climatic data on dynamics of proven and suspected vectors. The aims of this study are to better understand the spatial distribution and diversity of Culicoides in Senegal and to map their abundance throughout the country.
\end{abstract}

Methods: Culicoides data were obtained through a nationwide trapping campaign organized in 2012. Two successive collection nights were carried out in 96 sites in 12 (of 14) regions of Senegal at the end of the rainy season (between September and October) using OVI (Onderstepoort Veterinary Institute) light traps. Three different modeling approaches were compared: the first consists in a spatial interpolation by ordinary kriging of Culicoides abundance data. The two others consist in analyzing the relation between Culicoides abundance and environmental and climatic data to model abundance and investigate the environmental suitability; and were carried out by implementing generalized linear models and random forest models.

Results: A total of 1,373,929 specimens of the genus Culicoides belonging to at least 32 different species were collected in 96 sites during the survey. According to the RF (random forest) models which provided better estimates of abundances than Generalized Linear Models (GLM) models, environmental and climatic variables that influence species abundance were identified. Culicoides imicola, C. enderleini and C. miombo were mostly driven by average rainfall and minimum and maximum normalized difference vegetation index. Abundance of $C$. oxystoma was mostly determined by average rainfall and day temperature. Culicoides bolitinos had a particular trend; the environmental and climatic variables above had a lesser impact on its abundance. RF model prediction maps for the first four species showed high abundance in southern Senegal and in the groundnut basin area, whereas $C$. bolitinos was present in southern Senegal, but in much lower abundance.

(Continued on next page)

\footnotetext{
* Correspondence: myriem85@yahoo.fr

'InstitutSénégalais de Recherches Agricoles, Laboratoire National de l'Elevage

et de Recherches Vétérinaires, Dakar, Sénégal

¿Université Gaston Berger, Laboratoire d'Etudes et de Recherches en

Statistiques et Développement, Saint-Louis, Sénégal

Full list of author information is available at the end of the article
}

(c) The Author(s). 2018 Open Access This article is distributed under the terms of the Creative Commons Attribution 4.0 International License (http://creativecommons.org/licenses/by/4.0/), which permits unrestricted use, distribution, and reproduction in any medium, provided you give appropriate credit to the original author(s) and the source, provide a link to the Creative Commons license, and indicate if changes were made. The Creative Commons Public Domain Dedication waiver (http://creativecommons.org/publicdomain/zero/1.0/) applies to the data made available in this article, unless otherwise stated. 
(Continued from previous page)

Conclusions: Environmental and climatic variables of importance that influence the spatial distribution of species abundance were identified. It is now crucial to evaluate the vector competence of major species and then combine the vector densities with densities of horses to quantify the risk of transmission of AHS virus across the country.

Keywords: Senegal, African horse sickness, Culicoides vectors, Environmental and climatic data, Random forest models, Generalized Linear Models, Spatial distribution, Mapping

\section{Background}

African horse sickness (AHS) and Bluetongue (BT) are vector-borne viral diseases affecting equids and ruminants (mainly cattle and small ruminants), respectively. These two viruses are biologically transmitted by females of several species of Culicoides (Diptera: Ceratopogonidae) biting midges. Bluetongue is distributed worldwide, affecting almost all continents (except Antarctica) while AHS occurs in sub-Saharan Africa, with rare incursions into Europe and Asia [1-3]. The importance of these two arboviral diseases derives from their potential for rapid spread and their major economic impact due to direct mortalities, restriction of animal movements, surveillance and vaccination costs, as shown by the recent outbreaks of BT in Europe [4-6] and AHS in Africa [7, 8]. Their importance requires immediate notification to the World Animal Health Organization [9].

Following the important AHS outbreak in Senegal in $2007[7,8]$, several studies were initiated in the Niayes area (in the western part of the country) in order to better characterize Culicoides diversity and ecology [10-14], and the impact of environmental and climatic variables on the dynamics of major vector species (proven and suspected vectors) [15]. These studies recorded for the first time the presence of Culicoides oxystoma and showed that this species was extremely abundant in the Niayes, both in black-light and in horse-baited traps. Because of its abundance, close contact with horses and its known or suspected role in the transmission of other arboviruses (Akabane, epizootic haemorrhagic disease and bluetongue viruses), these studies concluded that it should be considered as a potential vector of AHS virus. These studies also showed that Culicoides population peak of abundance occurred at end of the rainy season in September and October.

In order to anticipate future events, prevent and better control Culicoides-borne disease outbreaks, it is essential to identify areas with higher risk of Culicoides-borne pathogens transmission at a national or regional level. This allows characterizing vector species distribution in Senegal. This is essential to determine if vectors are present throughout the country, if their abundance is highly variable or not and thus identify high-risk transmission areas. Combined with horse population distribution, this enables to target vaccination in these high-risk areas in the event of an outbreak. The first step towards this aim implies improving our knowledge on the distribution of vectors in
Senegal. Thus, a nation-wide entomological trapping campaign was carried out to model the abundance of proven and potential vectors of AHS virus (AHSV) and/or BT virus (BTV) in Senegal and map their distribution.

Several studies demonstrated the ability to predict the presence and/or abundance of Culicoides midges using meteorological and environmental variables mainly derived from satellite imagery. These models were established using statistical techniques such as discriminant analysis [16-20], generalized linear models such as logistic regression [21-25] and more recently, data-mining techniques such as random forests $[17,26,27]$.

The aim of this study is to model the spatial distribution of Culicoides species which are known or suspected to be vectors of AHSV and/or which are the most abundant in Senegal. The models could help stakeholders to make decisions for the control of these diseases. For this, entomological data were obtained through a nationwide trapping campaign and models for each species were developed to map their abundance. Three different modeling approaches were compared in order to find a simple yet robust method for each species. The first method consists in a spatial interpolation by ordinary kriging of Culicoides abundance data and does not necessitate environmental data. The other two consist of analyzing the relationship between Culicoides abundance, environmental and climatic data to model abundance in unsampled areas and were carried out by implementing generalized linear models and random forest models.

\section{Methods \\ Entomological data}

In 2012, a nationwide Culicoides trapping campaign was organized to collect information on the spatial distribution of Culicoides species in Senegal. Overall, with the help of the veterinary services, 108 sites holding equids were initially selected as follows: 3 sites per department and 3 departments per region in 12 (of the 14) regions of Senegal. Both the Institut Sénégalais de Recherches Agricoles (ISRA) team and veterinary services' officers carried out trapping over two consecutive collection nights in each site at the end of the rainy season (between September and October). This timeframe was chosen because it corresponds to the peak of abundance of Culicoides in the Niayes region [13-15, 28]. Geographical coordinates of 
sampling sites (Fig. 1) were recorded using Garmin $\odot$ global positioning system receivers (accurate to within 10 meters). Culicoides species were collected using Onderstepoort black-light suction traps (Onderstepoort Veterinary Institute South Africa) positioned close to equids (for further information on trap set up see [13, 14]). Identification of Culicoides species was carried out as explained by [13].

Maximum abundance of the two nights was considered as the best estimate of the population present as abundance can decrease rapidly in sub-optimal trapping conditions [29]. If the mean abundance between two nights is used instead of the maximum abundance, then the abundance recorded will be decreased in the sites. Mean is typically meaningful when data are normally distributed.
Maximum is much more meaningful here as we are sure that the site holds at least this number of Culicoides corrected by an unknown trap efficiency factor. Entomological data are provided in Additional file 1: Table S1.

\section{Climatic and environmental data}

Climatic and environmental variables characterizing favorable habitats for Culicoides were selected based on literature review of presence and abundance models [15-18, $20,26,30-37]$. A total of 21 variables were selected belonging to 5 categories (temperature, vegetation index, precipitation, land cover and livestock density). Climatic variables included day-time and night-time land surface temperature (DLST and NLST) and rainfall. Environmental variables
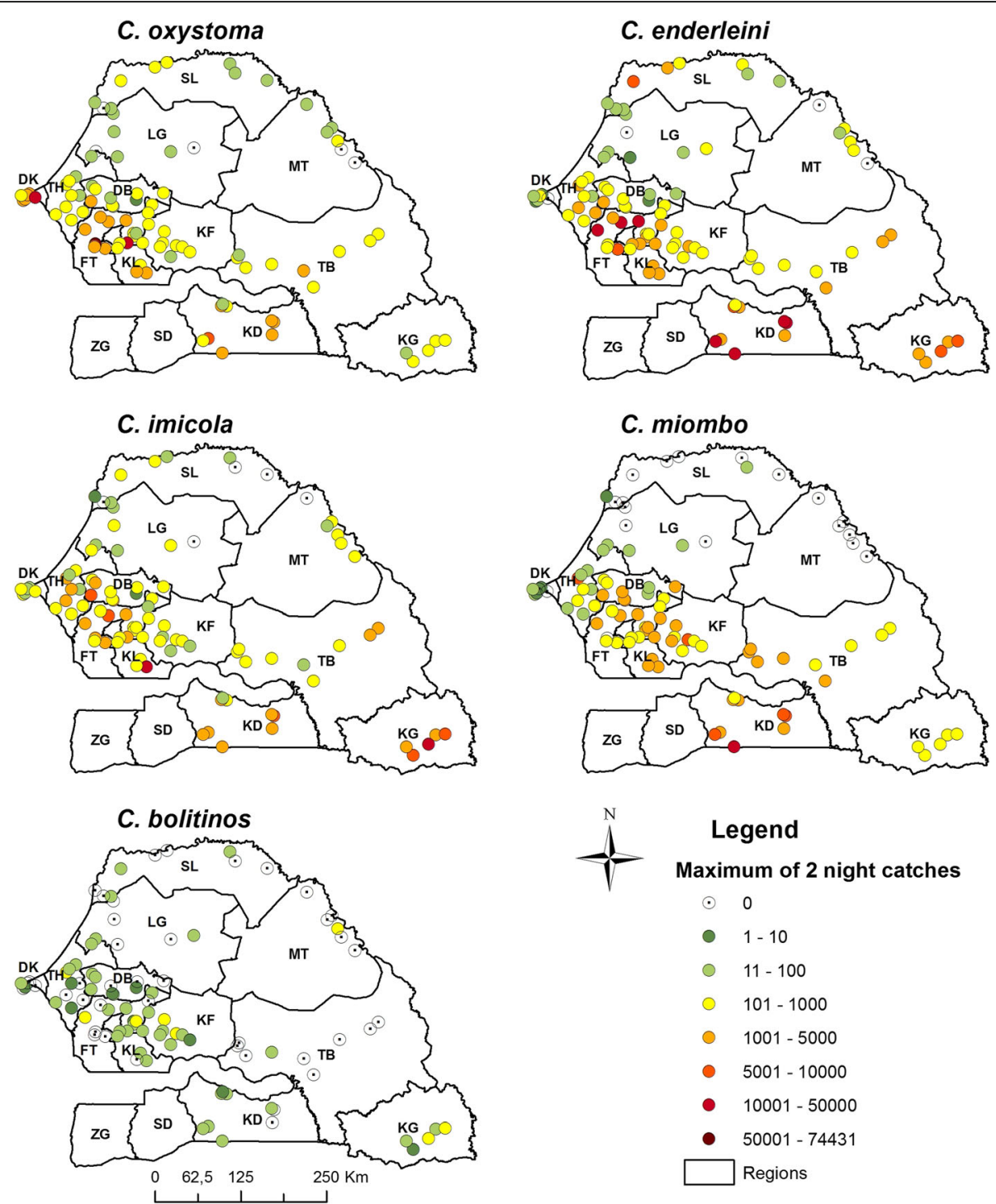

Fig. 1 Maximum abundance maps (2 nights of captures) for the five Culicoides species of veterinary interest in Senegal. Abbreviations: DK, Dakar; TH, Thies; DB, Diourbel; FT, Fatick; KF, Kaffrine; KL, Kaolack; LG, Louga; SL, Saint-Louis; MT, Matam; TB, Tambacounda; KD, Kedougou; KL, Kolda; SD, Sedhiou; ZG, Ziguinchor 
included the normalized difference vegetation index (NDVI), percentages of 3 land-cover classes (water, savannah and forest), and ruminant host densities.

Temperature, NDVI and rainfall were extracted from satellite images from September 1, 2011 to October 31, 2012. The DLST and NLST images were obtained from MODIS sensor (http://modis.gsfc.nasa.gov) and NDVI images were derived from Spot-Vegetation (https://rs.vito.be/ africa/en/data/Pages/vegetation.aspx). For DLST, NLST and NDVI, the maxima, minima and means were calculated for this 14 months period. Precipitation data were derived from National Oceanic and Atmospheric Administration (http://iridl.ldeo.columbia.edu/expert/ SOURCES/.NOAA/.NCEP/.CPC/.FEWS/.Africa/.DAILY/ .ARC2/.daily/.est_prcp/). The maximum, mean and cumulative rainfalls were calculated. Land cover data was derived from the Senegal Land Cover Database produced by the Food and Agriculture Organization of the United Nations (FAO) in the framework of Global Land Cover Network activities (http://www.fao.org/geonetwork/srv/en/ main.home?uuid=545be438-bc87-480b-83ec-ba3f4e486-

daf). Percentage of surface covered by water, particularly favorable for Culicoides $[15,26]$ savannah and forest in the $1 \mathrm{~km}^{2}$ pixels comprising the trap were extracted. Ruminant (cattle, sheep and goats) livestock density data was obtained from the global distribution of livestock maps produced by the FAO (http://www.fao.org/ag/againfo/resources/en/glw/GLW_dens.html).

All data layers were clipped on the Senegalese territory and projected in the same projection system with a spatial resolution of $1 \mathrm{~km}^{2}$ using R2.10.1 statistical language environment [38] using of the R-package: maps [39], mapdata [40], maptools [41], raster [42], rgdal [43] and sp [44]. Climatic data are provided in Additional file 2: Figure S1.

\section{Statistical analysis}

Three methods were used to map the abundances of targeted species of interest: ordinary kriging and two regression techniques: generalized linear models and random forests.

\section{Spatial interpolation by ordinary kriging}

Ordinary kriging is an interpolation technique that aims to predict the value of a variable in an unsampled site [45] taking into account the spatial dependence of the data. It enables converting point data (data measured in specific sample sites) into raster data (images). In spatial statistics, the empirical semivariance is described as follows:

$$
\gamma(h)=\frac{1}{2} \cdot \frac{1}{N(h)} \sum_{i=1}^{N(h)}\left(\left(z\left(x_{i}+h\right)-z\left(x_{i}\right)\right)^{2}\right.
$$

where, $z\left(x_{i}\right)$ are data at a particular location, $h$ is a distance between ordered data, $N(h)$ the number of paired data at a distance of $h$.
First experimental semi-variograms (a graph of semivariances versus distances between ordered data) are plotted to visualize statistical dependence values. Then a model is adjusted according to semivariogram's points to assess the statistical dependencies between sites and thus determine the maximal interpolation distance (over this distance interpolations can no longer be carried out).

\section{Generalized linear model}

One of the distributions commonly used to model count data is the Poisson distribution. However, this distribution assumes equidispersion of count data. Culicoides data generally show strong overdispersion [15]. Overdispersion was tested according to [46]. The statistical approach was planned as follows: in case of significant overdispersion of the residuals of the Poisson model, a negative binomial model was tested, and in case again of significant overdispersion of residuals of the negative binomial model, a hurdle model was tested $[47,48]$.

\section{Random Forest model}

Random Forest (RF) method is a robust ensemble learning technique for data analysis which consists of a set of classifications and regressions trees constructed from sub-samples of the complete data set [49]. This approach can be applied to model either the presence probability by performing classifications for qualitative variables (Random Forest classification) $[17,26,27]$ or abundances by performing regressions for quantitative variables (Random Regression Forest) [26]. For more information on RF models and their application to model Culicoides presence and abundance, see [26]. By bootstrapping the data and by randomly changing the predictive variable sets over the different tree, $\mathrm{RF}$ increase diversity among regression trees. Each of the $\mathrm{k}$ regression trees is grown using another bootstrap subset of the original data set and the nodes are split using the best split variable among a subset of $\mathrm{m}$ randomly selected predictive variables [50]. RF parameters, which are the number of trees $(\mathrm{k})$ and the number of predictive variables used to split the nodes $(\mathrm{m})$, are user-defined. In this study, to allow for error convergence, $\mathrm{k}$ was set to 500 and $\mathrm{m}$ to 4 .

The Root means squared error (RMSE) was calculated for internal validation of general linear models (GLM) and RF models. Statistical analysis and modeling were performed with the R2.10.1 statistical language environment [38] using of the R-package: rgdal [43], splancs [51], gstat [52], maptools [41] and randomForest [50].

\section{Results}

Between September, 17th and October, 14th 2012, among the 108 sites initially selected, 98 sites were sampled and 10 sites were not prospected because of logistical issues. In two of the 98 sampled sites the trapping results were not 
exploitable and thus were not considered (one conservation issue and one battery failure).

A total of 1,373,929 specimens of the genus Culicoides belonging to 32 different species were collected in 96 sites during the survey (Table 1). At least 32 species were collected; there may be other species among the $1.8 \%$ of captured Culicoides that were not identified. Among those specimens, some belong to the Milnei and Similis groups but could not be identified more precisely as one sex was missing. Some individuals belonging to the Imicola group were shown to world experts of Culicoides but could not be identified; at this stage it is unclear whether they are variants of known species or new species. Two species were recorded for the first time in Senegal: Culicoides murtalai [53] and Culicoides ochrothorax [54], increasing the number of described Culicoides species found in Senegal from 53 [14] to 55.

Table 1 Abundance and frequency of Culicoides species captured during the nationwide survey in Senegal

\begin{tabular}{|c|c|c|c|c|c|}
\hline Species & Total no. collected ${ }^{a}$ & Mean abundance per site/per night & $\%$ of catches & $\%$ of females & No. of positive sites (\%) \\
\hline C. oxystoma & 369,618 & 1925.04 & 26.9 & 85.46 & $93(96.88)$ \\
\hline C. enderleini ${ }^{\mathrm{b}}$ & 328,339 & 1710.09 & 23.89 & 86.79 & $92(95.83)$ \\
\hline C. imicola ${ }^{b}$ & 197,573 & 1029.02 & 14.38 & 86.95 & $92(95.83)$ \\
\hline C. miombo $o^{b}$ & 176,917 & 921.44 & 12.87 & 87.80 & 79 (82.29) \\
\hline C. trifasciellus & 147,917 & 770.40 & 10.76 & 97.76 & $54(56.25)$ \\
\hline C. milnei & 30,784 & 160.33 & 2.24 & 94.55 & $38(39.58)$ \\
\hline C. neavei & 29,958 & 156.03 & 2.18 & 96.91 & $27(28.13)$ \\
\hline C. kingi & 16,706 & 87.01 & 1.21 & 79.82 & $41(42.71)$ \\
\hline C. moreli & 14,978 & 78.01 & 1.09 & 85.69 & $54(56.25)$ \\
\hline C. leucostictus & 7277 & 37.90 & 0.53 & 74.71 & $53(55.21)$ \\
\hline C. nevilli & 6345 & 33.04 & 0.46 & 49.16 & $33(34.38)$ \\
\hline C. distinctipennis & 5131 & 26.72 & 0.37 & 70.10 & $25(26.04)$ \\
\hline C. quinquelineatus & 4783 & 24.91 & 0.34 & 91.26 & $21(21.88)$ \\
\hline C. bolitinos ${ }^{\mathrm{b}}$ & 4460 & 23.23 & 0.13 & 83.97 & $55(57.29)$ \\
\hline C. nivosus & 1894 & 9.86 & 0.09 & 83.54 & $34(35.42)$ \\
\hline C. fulvithorax & 1366 & 7.11 & 0.08 & 97.91 & $17(17.71)$ \\
\hline C. pseudopallidipennis & 1198 & 6.24 & 0.04 & 93.29 & $13(13.54)$ \\
\hline C. translucens & 614 & 3.19 & 0.03 & 34.56 & $14(14.58)$ \\
\hline C. accraensis & 504 & 2.62 & 0.03 & 58.86 & 19 (19.79) \\
\hline C. hortensis & 481 & 2.50 & 0.03 & 96.40 & $6(6.25)$ \\
\hline C. murtalai & 481 & 2.50 & 0.01 & 100 & $2(2.08)$ \\
\hline C. similis & 260 & 1.35 & 0.01 & 65.21 & $11(11.46)$ \\
\hline C. pycnostictus & 228 & 1.18 & $<0.01$ & 94.60 & $4(4.17)$ \\
\hline C. africanus & 91 & 0.47 & $<0.01$ & 100 & $4(4.17)$ \\
\hline C. austeni & 78 & 0.40 & $<0.01$ & 100 & $2(2.08)$ \\
\hline C. azerbajdzhanicus/C. ravus & 57 & 0.29 & $<0.01$ & 98.25 & $2(2.08)$ \\
\hline C. punctithorax & 45 & 0.23 & $<0.01$ & 4.48 & $2(2.08)$ \\
\hline C. ochrothorax & 42 & 0.21 & $<0.01$ & 100 & $1(1.04)$ \\
\hline C. yankari & 32 & 0.16 & $<0.01$ & 100 & $1(1.04)$ \\
\hline C. exspectator & 26 & 0.13 & $<0.01$ & 100 & $1(1.04)$ \\
\hline C. vomensis & 18 & 0.09 & $<0.01$ & 100 & $2(2.08)$ \\
\hline C. robini & 1 & 0.005 & $<0.01$ & 100 & $1(1.04)$ \\
\hline Culicoides sp. & 25,729 & 134.00 & 1.81 & 73.27 & - \\
\hline Total & $1,373,929$ & 7155.88 & 100 & 87.90 & - \\
\hline
\end{tabular}

${ }^{\mathrm{a}} 2$ nights, 96 sites

${ }^{\mathrm{b}}$ The five species of veterinary interest selected 
Each of the following five species represented more than $10 \%$ of the catch: Culicoides oxystoma, Culicoides enderleini, Culicoides imicola, Culicoides miombo and Culicoides trifasciellus. As found previously in the Niayes region, $C$. oxystoma (26.9\% of catches) was the most abundant species and was present in 93 out of the 96 sites sampled (97\% of sites). Percentages of individuals caught compared to the total (and frequencies of sites where the species was present) catches were $23.89 \%$ (95.83\%) for $C$. enderleini; $14.38 \%$ (95.83\%) for C. imicola; $12.87 \%$ (82.29\%) for C. miombo and $10.76 \%$ (56.25\%) for C. trifasciellus, respectively (Table 1 ).

We chose to model the distribution of five species: the first four most abundant (C. oxystoma, C. enderleini, $C$. imicola and C. miombo) and also Culicoides bolitinos as it is a proven vector of AHSV in South Africa [55]. Culicoides bolitinos was collected in low numbers $(0.32 \%$ of catches) and in $57.29 \%$ of the prospected sites.

For the five Culicoides species of veterinary interest, observed abundance data (maximum abundance of the two consecutive nights) are shown in Fig. 1. Overall, three species had similar (yet not identical) patterns: C. oxystoma, C. imicola and $C$. enderleini. They were abundant in the west (groundnut basin), in the south-east and in some sites in the north-east (river delta). The distribution of C. miombo differed mainly in that it was very rare in the north-eastern sites while the distribution of $C$. bolitinos was much sparser.

Regarding C. oxystoma, the sites where abundances were the highest are located in west central (Fatick, Kaolack and Diourbel regions), in the far west (Dakar region) and south of Senegal (Kolda region) (Fig. 2). For C. enderleini, the highest abundances were observed in the south (Kolda and Kedougou), in the groundnut basin (specifically in Fatick and Kaolack) and northwest of the Saint-Louis. For C. imicola, the highest abundances were recorded in the south and southeast (Kolda, Tambacounda and Kedougou) and in the center-west (Thies, Diourbel, Fatick and Kaolack). Culicoides miombo and $C$. bolitinos were very rare in northern Senegal. The highest abundances of $C$. miombo were obtained in Kolda, Tambacounda and in the groundnut basin (Fig. 2). Culicoides bolitinos abundances were very low. Culicoides bolitinos highest densities were noticed in

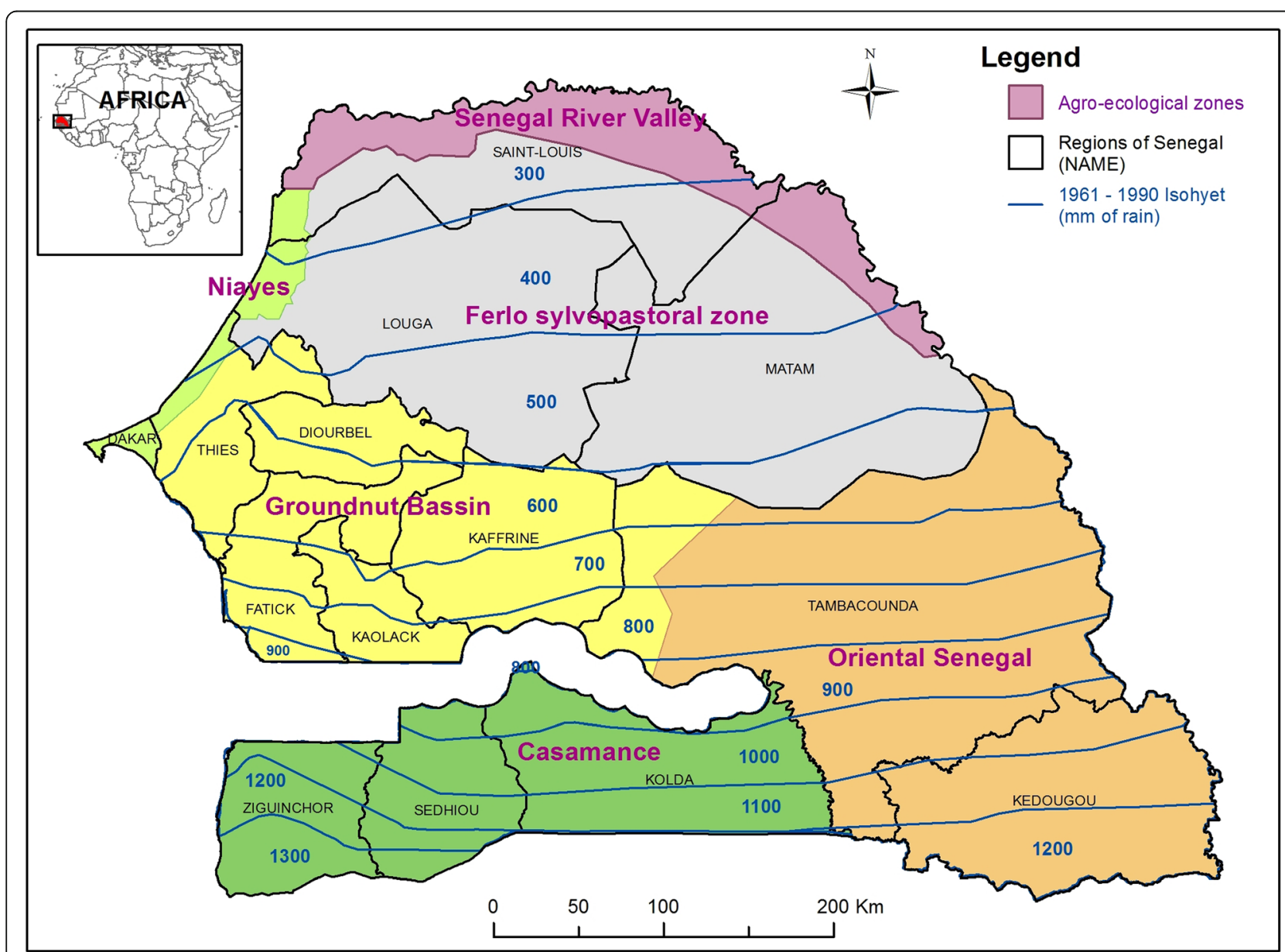

Fig. 2 Representation of isohyets (1961-1990) and delimitation of agroecological zones of Senegal. Source: Adapted from Centre de Suivi Ecologique du Sénégal (CSE) 
Kedougou region and in the groundnut basin (particularly in Fatick, Kaffrine and Kaolack).

The variogram results determined the maximal interpolation distances for each of the five species. These distances were: $20 \mathrm{~km}$ for C. oxystoma, $48 \mathrm{~km}$ for C. imicola, $13 \mathrm{~km}$ for C. enderleini, $25 \mathrm{~km}$ for C. miombo and 10 $\mathrm{km}$ for C. bolitinos (Fig. 3). Different models were fitted to the variograms: spherical models for C. oxystoma, C. imicola and C. bolitinos, a circular model for C. miombo and an exponential model for $C$. enderleini. Abundance maps by ordinary kriging were developed respecting the maximal interpolation distance for each species (Fig. 4). For C. oxystoma, C. enderleini, C. imicola and C. miombo, abundances were predicted to be very high in west-central and southern Senegal and decrease gradually towards the north. However, high abundances of $C$. enderleini were predicted in the northwest of Senegal and, to a lesser extent, for C. oxystoma. For $C$. bolitinos, the highest abundances were modelled in the extreme south of Senegal and south of the groundnut basin (specifically in Kaffrine region).

To produce abundance maps for the entire Senegalese territory, GLM and RF models were developed. Table 2 presents the 10 most important predictors for each species according to GLM models. Maximum NDVI was among the three most important variables for all species. Average rainfall was also among the 3 most important variables for 3 of the 5 species (C. oxystoma, C. enderleini and C. imicola). Other environmental variables that influence Culicoides abundances were day and night temperatures and percentage cover of water bodies for C. oxystoma and $C$. imicola; night temperatures for C. enderleini; day and night temperatures for $C$. miombo; livestock density and percentage cover of savannah for $C$. bolitinos. Abundance maps based on GLM modeling showed that for all five species of veterinary interest, predicted abundances are very low along the Senegal River Valley and very high in
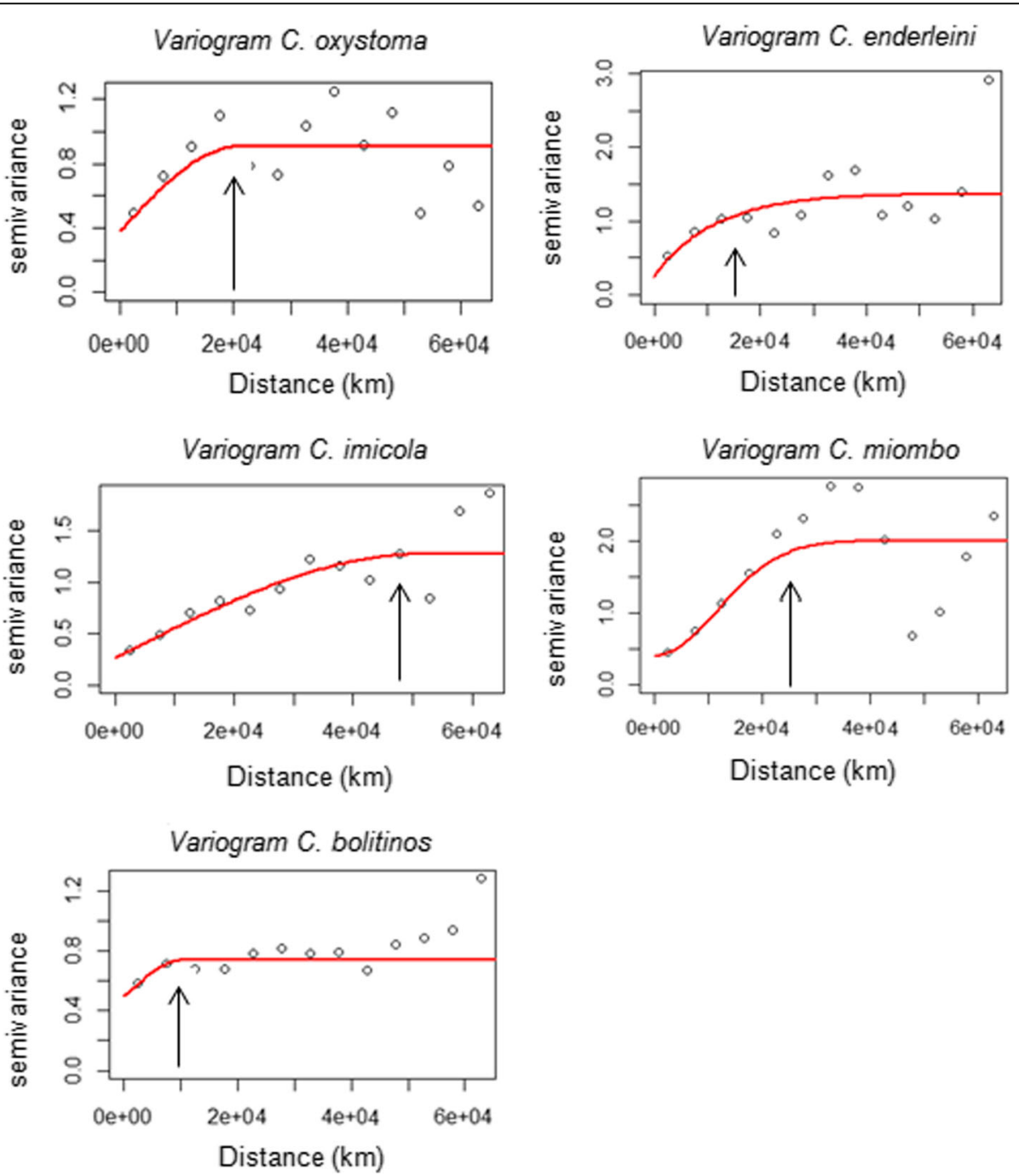

Fig. 3 Variogram models for each of the five Culicoides species of veterinary interest in Senegal 


\section{C. oxystoma}

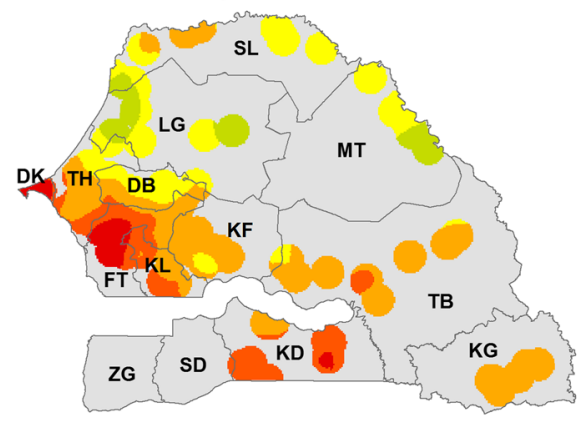

C. imicola

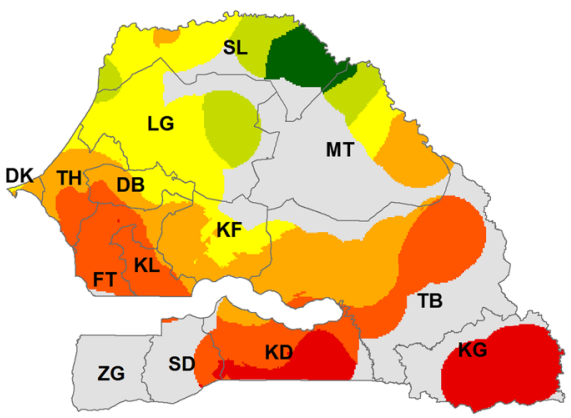

C. bolitinos

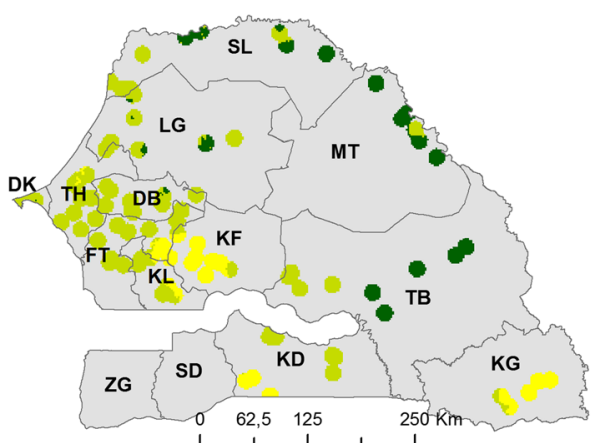

C. enderleini

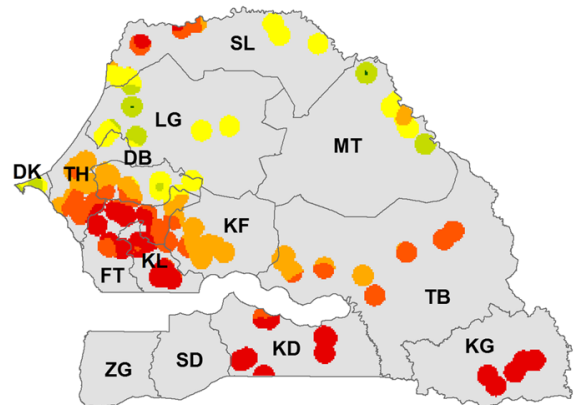

C. miombo
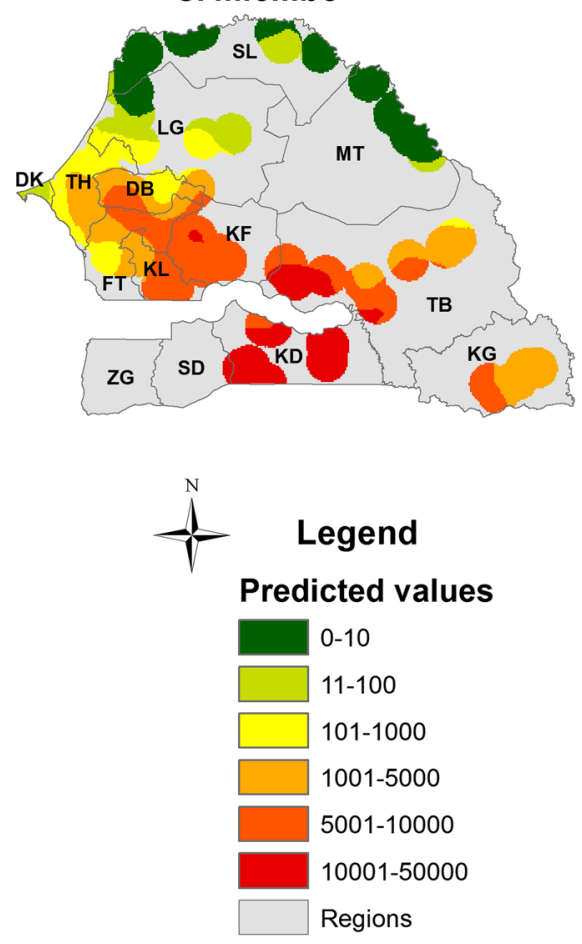

Fig. 4 Abundance maps obtained by ordinary kriging for the five Culicoides species in Senegal. Abbreviations: DK, Dakar; TH, Thies; DB, Diourbel; FT, Fatick; KF, Kaffrine; KL, Kaolack; LG, Louga; SL, Saint-Louis; MT, Matam; TB, Tambacounda; KD, Kedougou; KL, Kolda; SD, Sedhiou; ZG, Ziguinchor

the south (Fig. 5). High abundances of C. imicola and $C$. oxystoma are predicted on the entire country although for C. imicola areas of high and low abundance are strongly interlinked (areas of high abundance are often close to areas of low abundance). Culicoides imicola and C. enderleini predicted abundances are particularly strong in the southern third of the country and medium in the middle third. The distribution of $C$. miombo in the south is even more pronounced: abundant in the southern third, it is less abundant in the central and almost absent in the northern third of the country. Not surprisingly, C. bolitinos predicted abundances are lower than those of the other species. The area where it is most abundant is the delta in Casamance in southeast Senegal and in southwest Senegal (Fig. 5).
Table 3 lists the 10 most important predictor variables from RF model of the different Culicoides species. Rainfall and/or NDVI were the most important variables influencing the abundance of the five Culicoides species. This is particularly true for C. imicola, C. enderleini and C. miombo, since the 3 most important variables are average rainfall and minimum and maximum NDVI. Abundance of $C$. oxystoma was mostly determined by average rainfall and day temperature and less so by NDVI (only ranked 7th by order of importance). Abundance of $C$. enderleini was mostly determined by average precipitation, NDVI (minimum and maximum) and average day temperature; that of $C$. imicola by average precipitation and maximum NDVI. Abundance of $C$. miombo was mostly driven by maximum NDVI followed 
Table 2 The 10 most important predictors according to GLM model, indicated by the variable importance (Varlmp) for the five Culicoides species of veterinary interest

\begin{tabular}{|c|c|c|c|c|c|c|c|c|c|}
\hline \multicolumn{2}{|l|}{ C. oxystoma } & \multicolumn{2}{|c|}{ C. enderleini } & \multicolumn{2}{|l|}{ C. imicola } & \multicolumn{2}{|l|}{ C. miombo } & \multicolumn{2}{|l|}{ C. bolitinos } \\
\hline Predictors & Varlmp & Predictor & Varlmp & Predictor & Varlmp & Predictor & Varlmp & Predictor & Varlmp \\
\hline$\overline{\text { AvRain }^{a}}$ & 83 & MaxNDVl $^{a}$ & 100 & AvRain $^{a}$ & 74 & MaxNDVl $\left.\right|^{a}$ & 100 & MaxNDVl| & 72 \\
\hline MaxNDVla & 74 & AvRain $^{a}$ & 64 & MinNDVl $\left.\right|^{a}$ & 58 & $\mathrm{MinNDVI}^{a}$ & 98 & AvHost $^{a}$ & 64 \\
\hline MinDlst $^{a}$ & 62 & MinNDV| $\left.\right|^{a}$ & 58 & MaxNDVI & 34 & MaxNlst ${ }^{a}$ & 87 & IcSavanha & 63 \\
\hline MaxNlst ${ }^{a}$ & 57 & MaxNlst & 39 & MaxNlst & 32 & MinDlst $^{a}$ & 68 & MaxDlst & 47 \\
\hline MinNlst & 37 & MinNlst & 33 & MinDlst & 32 & AvHost & 37 & MaxNlst & 36 \\
\hline IcWater & 35 & MaxRain & 28 & IcWater & 28 & AvRain & 36 & avDlst & 30 \\
\hline MinNDVI & 22 & IcWater & 17 & avNlst & 27 & AvDlst & 21 & IcForest & 16 \\
\hline MaxRain & 18 & AvDlst & 13 & avDlst & 27 & MaxRain & 15 & IcWater & 14 \\
\hline AvDlst & 14 & IcForest & 11 & AvHost & 25 & AvRain & 12 & AvRain & 10 \\
\hline AvHost & 12 & MinDlst & 8 & MaxRain & 23 & IcWater & 8 & MinDlst & 6 \\
\hline
\end{tabular}

Abbreviations: $A V$ average, Min minimum, Max maximum, Dlst day land surface temperature, Nlst night land surface temperature, Ic landcover, NDVI normalized difference vegetation index, Host livestock density

a Predictors for which Varlmp are greater than $50 \%$

by average precipitation, minimum NDVI and average night temperature. Culicoides bolitinos had a particular trend; the above environmental and climatic variables had a lesser impact on its abundance.

Predicted Culicoides abundance maps provided by RF model are shown in Fig. 6. For the five species, an increasing abundance gradient from north to south is predicted. For C. oxystoma, C. enderleini and $C$. imicola, predicted abundances are very high in the southern third of the country, and for C. miombo abundances are high to very high in the southern and middle thirds. For all the species, predicted abundances are very low in the north of the country, particularly in the north of Ferlo and in the Senegal River valley. Culicoides oxystoma is predicted to be particularly abundant along the western coast from Dakar to Ziguinchor and in The Gambia along the river. This species also has very high predicted abundances in the south, southeast and center-west of Senegal (Fig. 6). Culicoides enderleini and C. imicola exhibit a similar pattern with very high abundances predicted in Casamance (Ziguinchor, Sedhiou and Kolda), eastern Senegal (Tambacounda and Kedougou) and the center-west of the groundnut basin (Fatick and surrounding). Regarding C. miombo and C. bolitinos, very low abundances were predicted in the Niayes' area. Culicoides bolitinos predicted abundances are lower than those of other species; the area where its abundance is predicted to be the highest is the south and southeast, particularly in Kedougou region.

Prediction errors measured by RMSE (on $\log _{10}(\mathrm{n}+1)$ scale) between observed and predicted values are lower for the RF model than for the GLM model for all five species (Table 4). Among RF models, predictions errors are lowest for C. imicola (RMSE $=0.31$ ).

\section{Discussion}

The identification of suitable areas for five targeted Culicoides species in Senegal was performed with three different modelling techniques: a spatial interpolation method, kriging and two statistical modelling methods using meteorological and environmental variables, GLM and RF models. Interpolation by kriging yielded incomplete prediction maps. To obtain complete maps, more intensive entomological survey would be necessary, especially for $C$. bolitinos and C. enderleini. Given the logistical efforts required to conduct such survey and identify Culicoides species, this option seems unrealistic.

The comparison of predicted abundance maps from each model showed consistent spatial structures. Although the predictions of maximum abundances provided by kriging were limited by extrapolation distances, abundance maps by kriging and RF models identified similar structures whereas GLM models provided abundance maps slightly different from those resulting from kriging and RF models. GLM outcomes differed for $C$. oxystoma particularly in Tambacounda and Kedougou, for C. enderleini in Fatick, Kaffrine, Kaolack and western Saint-Louis, for C. imicola in Thies, Fatick, Kaolack, for C. miombo in Dakar, Kaffrine and Tambacounda and for C. bolitinos in Kaolack, Kaffrine and Fatick.

Prediction errors between observed and predicted abundances were lower for the RF model than for the GLM model. Recent studies have also shown that RF approaches provide good modelling results both for regression [26] and classification [17, 26, 27] trees. The effect of climatic and environmental variables will be discussed for each species based on the results from RF models since they provided better estimates of abundances.

Regarding C. oxystoma, this is, to our knowledge, the first spatial distribution model published. Studies on 


\section{C. oxystoma}

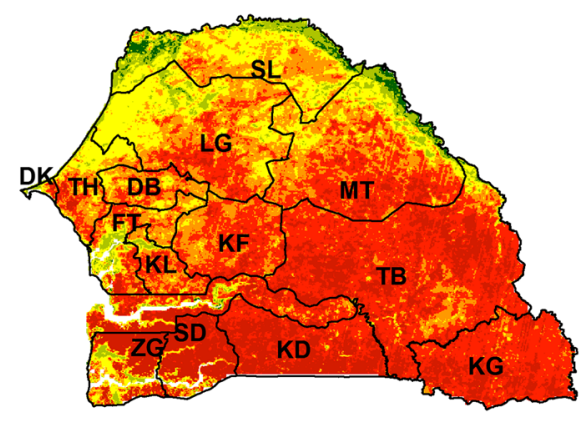

C. imicola

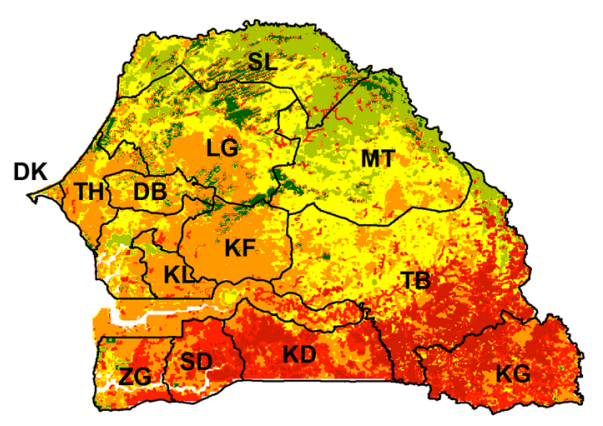

C. enderleini

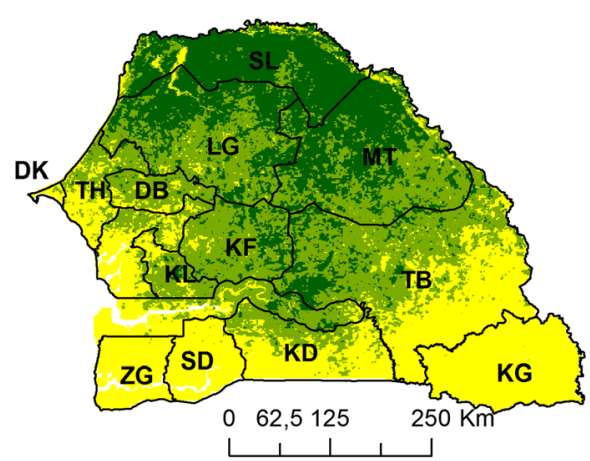

\section{C. enderleini}

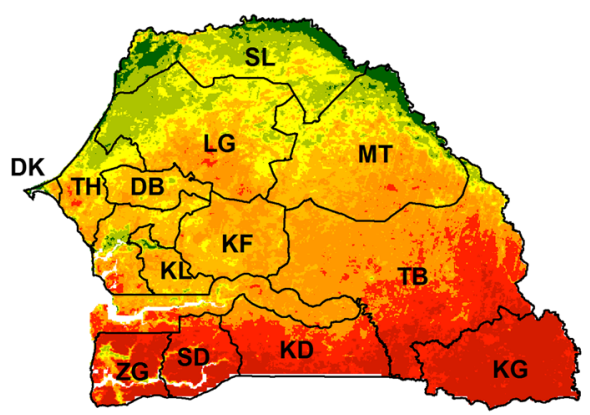

C. miombo
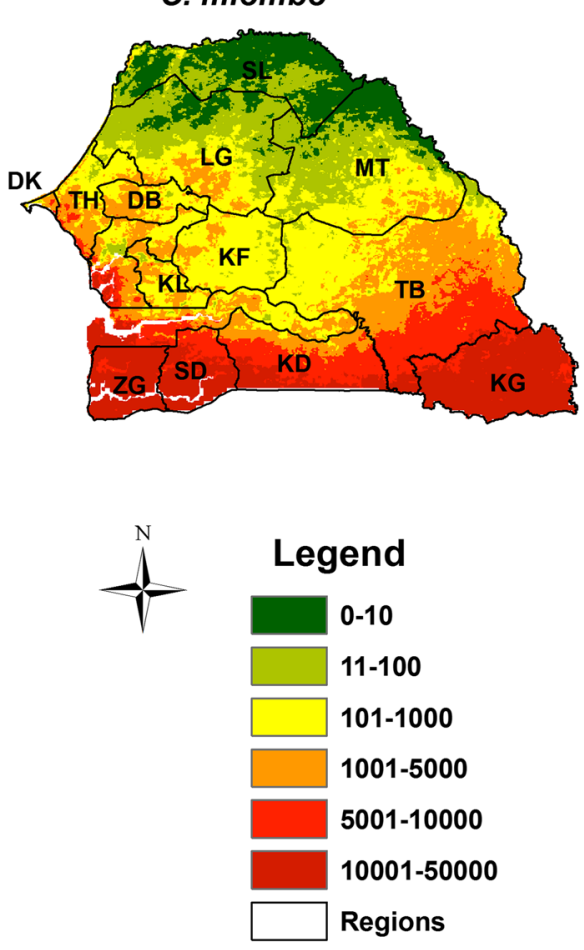

Fig. 5 Predicted abundance maps according GLM model for five Culicoides species of veterinary interest in Senegal. Abbreviations: DK, Dakar; TH, Thies; DB, Diourbel; FT, Fatick; KF, Kaffrine; KL, Kaolack; LG, Louga; SL, Saint-Louis; MT, Matam; TB, Tambacounda; KD, Kedougou; KL, Kolda; SD, Sedhiou; ZG, Ziguinchor

Culicoides dynamics in Senegal show that this species is very frequent and abundant in the Niayes area [13, 14]. Our study shows that this species is widespread and abundant over the entire country, with an increasing gradient from north to south, and high predicted abundance in the west, near the coast and around river deltas.

Average rainfall was the most important variable influencing C. oxystoma, C. enderleini and C. imicola abundance, and the second most important variable for C. miombo. This variable seems to limit the abundance of these species in the north, more arid (see isohyets representation of Senegal in Fig. 2). In addition to rainfall, day and night temperatures strongly influenced C. oxystoma abundance. Its highest abundance was observed in the groundnut basin and southern Senegal. Although ecological drivers of $C$. oxystoma remain poorly described, this species is known to be abundant in South Korea [56] and in Kagoshima, southern Japan [57]. These two areas are characterized by a humid subtropical climate. Culicoides oxystoma was collected from May to October in the south of Korea [56] and from May to November in southern Japan [57], i.e. in the warmer and rainy period of the year, showing that rainfall and temperature appear to influence the distribution of this species in both Japan and in Senegal. 
Table 3 The 10 most important predictors according to the RF model, indicated by the variable importance (Varlmp) for the five Culicoides species of veterinary interest

\begin{tabular}{|c|c|c|c|c|c|c|c|c|c|}
\hline \multicolumn{2}{|c|}{ C. oxystoma } & \multicolumn{2}{|c|}{ C. enderleini } & \multicolumn{2}{|l|}{ C. imicola } & \multicolumn{2}{|l|}{ C. miombo } & \multicolumn{2}{|l|}{ C. bolitinos } \\
\hline Predictor & Varlmp & Predictor & Varlmp & Predictor & Varlmp & Predictor & Varlmp & Predictor & Varlmp \\
\hline AvRain $^{\text {b }}$ & 13.54 & AvRain $^{b}$ & 13.40 & AvRain $^{b}$ & 18.82 & MaxNDVI $^{a}$ & 47.42 & $\operatorname{MaxNDVl}^{c}$ & 6.31 \\
\hline AvDlst $^{b}$ & 11.41 & MinNDVI ${ }^{b}$ & 13.16 & MaxNDVI ${ }^{b}$ & 10.37 & AvRain ${ }^{b}$ & 20.64 & $\mathrm{AvHost}^{\mathrm{c}}$ & 5.91 \\
\hline MaxDlst ${ }^{c}$ & 6.07 & MaxNDVl $^{b}$ & 11.87 & MinNDVI & 8.42 & MinNDVI $^{b}$ & 11.15 & MinDlst ${ }^{c}$ & 5.66 \\
\hline MinNlst ${ }^{c}$ & 5.96 & AvDlst $^{b}$ & 11.08 & MaxRain ${ }^{c}$ & 6.19 & AvNlst $^{b}$ & 10.51 & MaxDlst ${ }^{c}$ & 5.65 \\
\hline $\mathrm{AvNlst}^{\mathrm{C}}$ & 5.47 & MaxDlst ${ }^{c}$ & 8.13 & $\mathrm{AvN} \mathrm{st} \mathrm{c}^{\mathrm{C}}$ & 5.66 & MaxNlst ${ }^{c}$ & 9.50 & AvDlst $^{c}$ & 5.64 \\
\hline MinDlst ${ }^{c}$ & 5.32 & MaxRainc & 6.35 & AvDlst $^{c}$ & 5.25 & MaxDlst ${ }^{c}$ & 8.88 & MaxNIst ${ }^{c}$ & 5.30 \\
\hline $\operatorname{MaxNDVl^{c}}$ & 5.04 & MinNlst ${ }^{c}$ & 5.85 & MinNlst & 4.62 & MinNIst ${ }^{c}$ & 8.33 & $\operatorname{MinNDVl} l^{c}$ & 5.21 \\
\hline MaxRain & 4.93 & MinDlst $^{c}$ & 5.31 & MaxNlst & 4.37 & MaxRain ${ }^{c}$ & 7.25 & IcSavanha & 5.20 \\
\hline MaxNlst & 4.63 & $\mathrm{AvNlst}^{\mathrm{c}}$ & 5.16 & MinDlst & 4.09 & MinDlst ${ }^{c}$ & 6.91 & IcForest $^{c}$ & 5.13 \\
\hline AvHost & 4.08 & AvHost & 4.43 & MaxDlst & 3.45 & AvDlst $^{c}$ & 6.81 & IcWater & 4.72 \\
\hline
\end{tabular}

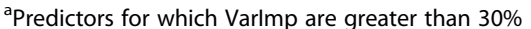

${ }^{b}$ Predictors for which Varlmp are lower than $30 \%$ and greater than $10 \%$

'Predictors for which Varlmp are lower than 10\% and greater than $5 \%$

Livestock density seems to have a weak influence on $C$. oxystoma abundances. Generally, livestock density was not identified as a variable with a high impact on Culicoides abundance except for C. bolitinos. This is surprising because for many other Culicoides species, especially those vectors of pathogens to animals, the presence of hosts and their density are key factors known to affect their catch [58-60]. Several reasons might explain this outcome. First, host densities data was available at a low spatial resolution $(100 \times 100 \mathrm{~km})$. Secondly, these consisted in 2005 predictions, and densities could have changed (increased or decreased) since then. Thirdly, host densities included only three ruminant species (cattle, sheep and goats) but did not include horse densities. To our knowledge there is no map of horse densities available for Senegal. The lack of data on horse densities could be an important hindrance since in the field, in Senegal, Fall et al. [61] found high abundances of $C$. oxystoma on horses. Finally, some Culicoides species are able to feed on other hosts, including birds and wildlife, and it is possible that the densities of these other host species impact the distribution of that species.

As for C. oxystoma, little information in the literature is available on climatic and environmental variables that could impact $C$. enderleini. In this study, C. enderleini was very abundant in the southern third of the country. RF models showed that its abundance is significantly associated with rainfall, vegetation index, day and night temperatures and, to a lesser extent, livestock density. This is coherent since in the south of Senegal, rainfall is important, average NDVI, temperatures and livestock density are high.

The distribution of C. imicola and C. enderleini followed a similar pattern with an increasing north-south gradient. Again, average rainfall could be a limiting factor in the north, explaining higher abundances in the south (Ziguinchor, Kolda and Kedougou) and center-west (in the groundnut basin) regions that record the highest rainfall in Senegal. The importance of rainfall on the distribution and abundance of C. imicola was highlighted in Morocco [33] and Europe [22, 26, 37, 62]. The study of Culicoides dynamics in the Niayes area also showed that peaks of abundance of C. imicola occurred during the end of the rainy season (September-October) [13].

Maximum and minimum NDVI were the second and third most important variables associated with $C$. imicola abundance. The link between the distribution of C. imicola and NDVI is consistent with previous studies showing that high NDVI values were associated with increased C. imicola abundance in the Niayes area in Senegal [15], in north Africa and in Europe [16, 24, 30-33]. In Senegal, areas where the vegetation index is the highest are also those where rainfall is highest, as both are linked [63]. Studies have also highlighted the link between NDVI and soil moisture [64]. Soil moisture could be an important factor influencing larval development of this species. Temperatures (day and night) were also found associated with C. imicola abundance. This finding has been confirmed by several other studies $[16,18,19,25,29,32,35]$.

Concerning C. miombo, maximum NDVI was by far the most important variable influencing its abundance. Its highest abundances were recorded in areas where the vegetation index is the highest, i.e. in the groundnut basin and in southern Senegal. In the north of the country where the vegetation index is the lowest, C. miombo is almost absent. In the Niayes area (particularly in Dakar and Thies), the abundance of C. miombo was low, confirming the results of a previous study [13]. This is probably due to the low vegetation index in this area. In this study, rainfall and temperatures were found associated with the abundance of C. miombo, in coherence with 


\section{C. oxystoma}

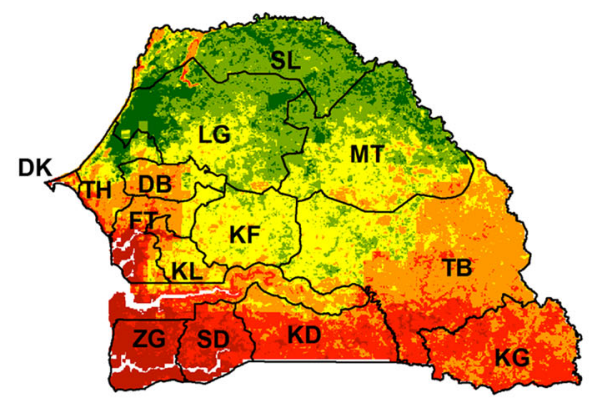

C. imicola

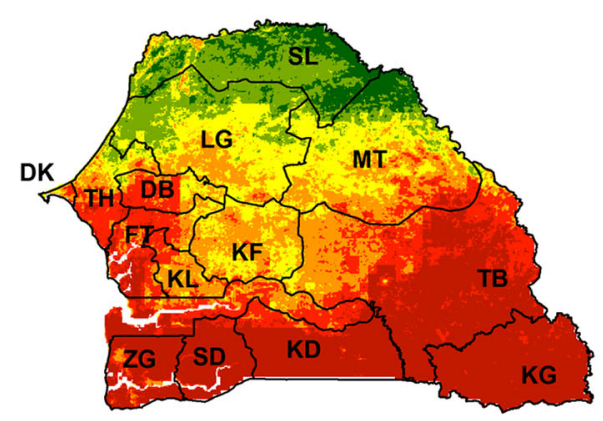

C. bolitinos

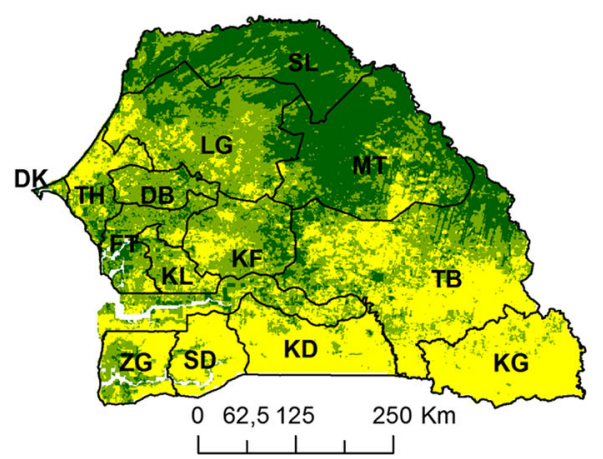

C. enderleini

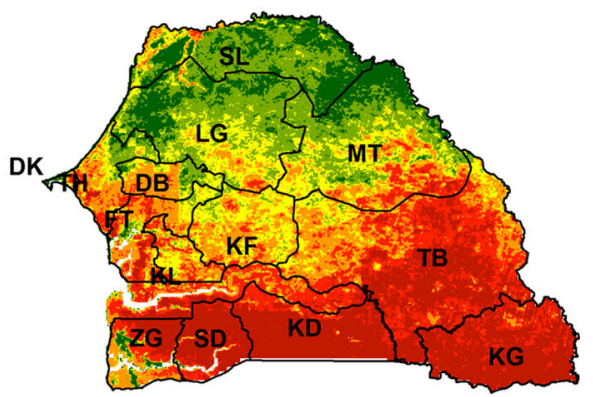

C. miombo

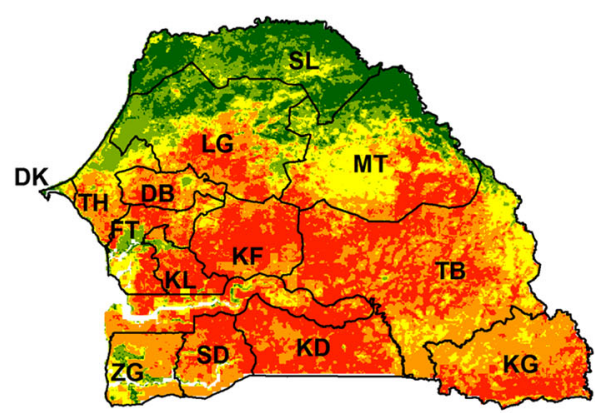

\section{Legend}

Predicted values

0-10

11-100

101-1000

1001-5000

5001-10000

10001-50000

Regions

Fig. 6 Predicted abundance maps according RF model for five Culicoides species of veterinary interest in Senegal. Abbreviations: DK, Dakar; TH, Thies; DB, Diourbel; FT, Fatick; KF, Kaffrine; KL, Kaolack; LG, Louga; SL, Saint-Louis; MT, Matam; TB, Tambacounda; KD, Kedougou; KL, Kolda; SD, Sedhiou; ZG, Ziguinchor

Table 4 Internal validation (root means squared error (RMSE) on $\log _{10}(n+1)$ scale) of GLM and RF models for each of the five species of veterinary interest

\begin{tabular}{lll}
\hline Species & RMSE & \\
\cline { 2 - 3 } & GLM & RF \\
\hline C. oxystoma & 1.72 & 0.33 \\
C. enderleini & 1.9 & 0.37 \\
C. imicola & 1.75 & 0.31 \\
C. miombo & 1.36 & 0.37 \\
C. bolitinos & 1.42 & 0.38 \\
\hline
\end{tabular}

Meiswinkel's study, which revealed that this species is sensitive to rainfall and high temperatures [65].

Regarding C. bolitinos, no single variable was a dominant driver of its abundance. Indeed, the contribution of the best environmental predictor (maximum NDVI) on its abundance remained very low (variable importance $=6.31$ ). The most important variables impacting its abundance were the NDVI, livestock density and temperature. These three types of variables have also been linked to $C$. bolitinos abundance in South Africa [66]. Livestock density was an important variable which greatly impacted model accuracy. Studies conducted by Fall et al. [61] showed that C. bolitinos is 
particularly aggressive on horses with a blood-feeding rate of over $75 \%$. This species is also known to feed on large mammals [67]. Other studies describe the larval habitats of C. bolitinos as being the dung of wild and domestic Bovidae in Africa [68]. The ecology of this species is therefore closely linked to its hosts (through feeding and through its breeding media) and it is thus coherent to find a strong link to livestock densities and weaker environmental drivers of its abundance.

Overall, the highest abundances of these five species, proven or suspected vectors of AHS and BT viruses, were recorded in southern Senegal. If $C$. oxystoma seems present rather in the southwest of the country, $C$. enderleini, $C$. miombo and C. imicola have very high abundances in the center-south (Kolda), in the south-east (Kedougou) and in the groundnut basin. Culicoides abundance maps from RF models were compared with those of AHS outbreaks in 2007 in Senegal [8], which show significant mortality of horses in the groundnut basin. According to Diouf et al. [8], the greatest risk of introduction of AHS virus in Senegal is through the northeastern border because of important commercial trade movements and numerous markets to and from which carters transport goods. These authors suggested focusing surveillance of AHS virus introduction in that area in order to prevent the virus from reaching the groundnut basin where the dense network of markets could substantially amplify disease transmission and diffusion. Diouf et al. [8] considered the south and southeastern part of the country to be less at risk of AHS because of lower horse densities due to the presence of tsetse flies. Because low densities of Culicoides were found in the north-eastern part of Senegal, this study strengthens the hypothesis that the main driver of AHS introduction and spread in 2007 was horse movements. It confirms that the groundnut basin is an area at high risk of AHS transmission, because it combines important vector, host and market densities, which could lead to important epidemics. The very important densities of Culicoides in the south suggest that if the virus was present in the neighboring countries (Mali, the Republic of Guinea and Guinea Bissau), it could be introduced through the spread of infected Culicoides and then be amplified in donkeys.

The two main knowledge gaps to better assess AHS transmission risk in Senegal are (i) vector competence of suspected vectors and of very abundant species; and (ii) a map of equid (horse and donkey) densities. Assessing the vector competence for ASHV of species such as C. oxystoma, C. enderleini and C. miombo is essential to evaluate their roles in disease transmission. Mapping not only equid densities but also equid movement networks in Senegal would be of great help for decision makers, since combining vectors abundance maps with maps of equid densities and movements of equids would enable evaluation of AHS transmission risk. In a second step, combining transmission risk with AHS virus introduction risk would enable making recommendations in terms of early warning systems and vaccination policies.

\section{Conclusions}

To our knowledge, this study is the first to map the distribution of five major species of Culicoides of veterinary interest in Senegal. The highest abundances of Culicoides were observed in the south and in the groundnut basin, whereas abundances were the lowest in northern Senegal. Abundance maps were produced using three different modelling approaches. RF models provided better estimates of abundances than GLM models and were not limited by interpolation distances contrary to kriging. Environmental and climatic variables of importance that influence the spatial distribution of species abundance were identified. It is now crucial to evaluate the vector competence of major species and then combine the vector densities with densities of horses and ruminants to quantify the risk of transmission of AHS and BT virus across the country.

\section{Additional files}

Additional file 1: Table S1. Culicoides data from Senegal throughout a nation-wide trapping campaign in 2012. (XLSX 15 kb)

Additional file 2: Figure S1. Climatic and environmental data on Senegalese territory with a spatial resolution on $1 \mathrm{~km}^{2}$. Abbreviations: Av, Average; Min, Minimum; Max, Maximum; Dlst, Day land surface temperature; Nlst, Night land surface temperature; Ic, landcover; NDVI, Normalized difference vegetation index; Host, livestock density. (PDF 308 kb)

\section{Abbreviations}

AHSV: African horse sickness virus; BTV: Bluetongue virus; DLST: Day-time land surface temperature; GLM: Generalized Linear Models; NDVI: Normalized difference vegetation index; NLST: Night-time land surface temperature; RF: Random Forest

\section{Acknowledgements}

We thank the veterinary services of Senegal for helping us organize and carry out the trapping campaign. We thank the horse owners for allowing us access to their holdings. We thank Dr Thomas Balenghien and Dr Claire Garros for the Culicoides identification training session they organized at ISRA. We also thank Dr Claire Garros for her constructive comments on the manuscript.

\section{Funding}

This study was funded by EU grant FP7-261504 EDENext and is catalogued by the EDENext Steering Committee as EDENext389 (http://www.edenext.eu). The contents of this publication are the sole responsibility of the authors and do not necessarily reflect the views of the European Commission.

\section{Availability of data and materials}

Data supporting the conclusions of this article are included within the article and its additional files. Raw data are available from the corresponding author upon request.

\section{Authors' contributions}

HG, MD, AGF, MTS, AD and JB designed and supervised the study. MF, AGF, $M D$ and MTS performed sampling and global management of the entomological material. RL extracted climatic and environmental data. MF performed the species identification with the help of XA and IR. MD and HG analyzed the data and wrote the first draft of the manuscript. All authors read and approved the final manuscript. 


\section{Ethics approval and consent to participate}

Not applicable.

\section{Competing interests}

The authors declare that they have no competing interests.

\section{Publisher's Note}

Springer Nature remains neutral with regard to jurisdictional claims in published maps and institutional affiliations.

\section{Author details}

${ }^{1}$ InstitutSénégalais de Recherches Agricoles, Laboratoire National de l'Elevage et de Recherches Vétérinaires, Dakar, Sénégal. 'Université Gaston Berger, Laboratoire d'Etudes et de Recherches en Statistiques et Développement, Saint-Louis, Sénégal. ${ }^{3}$ Institut Pasteur de Dakar, G4 Biostatistique, Bioinformatique et Modélisation, Dakar, Sénégal. ${ }^{4}$ CIRAD, ASTRE, Montpellier, France. ${ }^{5}$ ASTRE, INRA, CIRAD, Univ Montpellier, Montpellier, France. ${ }^{6} \mathrm{Cirad}$, ASTRE, Antananarivo, Madagascar. ${ }^{7}$ Institut Pasteur, Epidemiology Unit, Antananarivo, Madagascar. ${ }^{8}$ FOFIFA, DRZVP, Antananarivo, Madagascar.

\section{Received: 12 October 2017 Accepted: 27 May 2018}

\section{Published online: 08 June 2018}

\section{References}

1. Bessell PR, Searle KR, Auty HK, Handel IG, Purse BV, Bronsvoort BM. Assessing the potential for Bluetongue virus 8 to spread and vaccination strategies in Scotland. Sci Rep. 2016;6:38940.

2. Carpenter S, Mellor PS, Fall AG, Garros C, Venter GJ. African horse sickness virus: history, transmission, and current status. Annu Rev Entomol. 2017;62: 343-58.

3. Mellor PS, Hamblin C. African horse sickness. Vet Res. 2004;35:445-66.

4. Maclachlan NJ, Guthrie AJ. Re-emergence of bluetongue, African horse sickness, and other Orbivirus diseases. Vet Res. 2010;41:35.

5. Tago D, Hammitt JK, Thomas A, Raboisson D. Cost assessment of the movement restriction policy in France during the 2006 bluetongue virus episode (BTV-8). Prev Vet Med. 2014;117:577-89.

6. Velthuis AGJ, Saatkamp HW, Mourits MCM, de Koeijer AA, Elbers ARW Financial consequences of the Dutch bluetongue serotype 8 epidemics of 2006 and 2007. Prev Vet Med. 2010;93:294-304.

7. Akakpo AJ, Wombou Toukam CM, Mankor A, Ly C. Impact économique de l'épizootie de peste équine de 2007 au Sénégal. Bull Anim Hlth Prod Afr. 2011;59:1-16

8. Diouf ND, Etter E, Lo MM, Lo M, Akakpo AJ. Outbreaks of African horse sickness in Senegal and methods of control of the 2007 epidemic. Vet Rec. 2013;172:152.

9. OIE. OIE-Listed diseases, infections and infestations in force in 2017. 2017. http://www.oie.int/en/animal-health-in-the-world/oie-listed-diseases-2017/. Accessed 21 June 2017.

10. Bakhoum MT, Fall AG, Fall M, Bassene CK, Baldet T, Seck MT, et al. Insight on the larval habitat of Afrotropical Culicoides Latreille (Diptera: (eratopogonidae) in the Niayes area of Senegal, West Africa. Parasit Vectors. 2016;9:462.

11. Bakhoum MT, Fall M, Fall AG, Bellis GA, Gottlieb Y, Labuschagne $K$, et al. First record of Culicoides oxystoma Kieffer and diversity of species within the Schultzei group of Culicoides Latreille (Diptera: Ceratopogonidae) biting midges in Senegal. PLoS One. 2013;8:e84316.

12. Bakhoum MT, Fall M, Seck MT, Gardes L, Fall AG, Diop M, et al. Foraging range of arthropods with veterinary interest: new insights for Afrotropical Culicoides biting midges (Diptera: Ceratopogonidae) using the ring method. Acta Trop. 2016;157:59-67.

13. Diarra M, Fall M, Fall AG, Diop A, Seck MT, Garros C, et al. Seasonal dynamics of Culicoides (Diptera: Ceratopogonidae) biting midges, potential vectors of African horse sickness and bluetongue viruses in the Niayes area of Senegal. Parasit Vectors. 2014;7:147.

14. Fall M, Diarra M, Fall AG, Balenghien T, Seck MT, Bouyer J, et al. Culicoides (Diptera: Ceratopogonidae) midges, the vectors of African horse sickness virus - a host/vector contact study in the Niayes area of Senegal. Parasit Vectors. 2015:8:39.

15. Diarra M, Fall M, Lancelot R, Diop A, Fall AG, Dicko A, et al. Modelling the abundances of two major Culicoides (Diptera: Ceratopogonidae) species in the Niayes Area of Senegal. PLoS One. 2015;10:e0131021.
16. Baylis M, Mellor PS, Wittmann EJ, Rogers DJ. Prediction of areas around the Mediterranean at risk of bluetongue by modelling the distribution of its vector using satellite imaging. Vet Rec. 2001;149:639-43.

17. Cianci D, Hartemink N, Ibáñez-Justicia A. Modelling the potential spatia distribution of mosquito species using three different techniques. Int J Health Geogr. 2015;14:10.

18. Conte A, Ippoliti C, Savini L, Goffredo M, Meiswinkel R. Novel environmental factors influencing the distribution and abundance of Culicoides imicola and the Obsoletus Complex in Italy. Vet Ital. 2007;43:571-80.

19. Purse BV, Baylis M, Tatem AJ, Rogers DJ, Mellor PS, Van Ham M, et al. Predicting the risk of bluetongue through time: climate models of temporal patterns of outbreaks in Israel. Rev Sci Tech. 2004;23:761-75.

20. Tatem AJ, Baylis M, Mellor PS, Purse BV, Capela R, Pena I, Rogers DJ. Prediction of bluetongue vector distribution in Europe and north Africa using satellite imagery. Vet Microbiol. 2003:97:13-29.

21. Calistri P, Goffredo M, Caporale V, Meiswinkel R. The distribution of Culicoides imicola in Italy: application and evaluation of current Mediterranean models based on climate. J Vet Med B Infect Dis Vet Public Health. 2003;50:132-8.

22. Calvete C, Estrada R, Miranda MA, Borras D, Calvo JH, Lucientes J. Modelling the distributions and spatial coincidence of bluetongue vectors Culicoides imicola and the Culicoides obsoletus group throughout the Iberian Peninsula. Med Vet Entomol. 2008;22:124-34.

23. Conte A, Giovannini A, Savini L, Goffredo M, Calistri P, Meiswinkel R. The effect of climate on the presence of Culicoides imicola in Italy. J Vet Med B Infect Dis Vet Public Health. 2003;50:139-47.

24. Guis H. Geomatique et epidemiologie: caracterisation des paysages favorables à Culicoides imicola, vecteur de la fievre catarrhale ovine en Corse. These de doctorat es Science de la vie et de la santé. Besançon: Universite de Franche-Comté; 2007.

25. Wittmann E, Mellor P, Baylis M. Using climate data to map the potential distribution of Culicoides imicola (Diptera: Ceratopogonidae) in Europe. Rev Sci Tech. 2001;20:731-40.

26. Ducheyne E, Chueca MAM, Lucientes J, Calvete C, Estrada R, Boender GJ, et al. Abundance modelling of invasive and indigenous Culicoides species in Spain. Geospat Health. 2013:8:241-54

27. Peters J, De Baets B, Calvete C, Lucientes J, De Clercq E, Ducheyne E, Verhoest $\mathrm{N}$. Absence reduction in entomological surveillance data to improve niche-based distribution models for Culicoides imicola. Prev Vet Med. 2011;100:15-28.

28. Fall M, Fall A, Seck M, Bouyer J, Diarra M, Balenghien T, et al. Circadian activity of Culicoides oxystoma (Diptera: Ceratopogonidae), potential vector of bluetongue and African horse sickness viruses in the Niayes area, Senegal. Parasitol Res. 2015;114:3151-8.

29. Baylis M, el Hasnaoui H, Bouayoune H, Touti J, Mellor PS. The spatial and seasonal distribution of African horse sickness and its potential Culicoides vectors in Morocco. Med Vet Entomol. 1997;11:203-12.

30. Acevedo P, Ruiz-Fons F, Estrada R, Marquez AL, Miranda MA, Gortazar C, Lucientes J. A broad assessment of factors determining Culicoides imicola abundance: modelling the present and forecasting its future in climate change scenarios. PLoS One. 2010;5:e14236.

31. Baylis M, Bouayoune $H$, Touti J, El Hasnaoui $H$. Use of climatic data and satellite imagery to model the abundance of Culicoides imicola, the vector of African horse sickness virus, in Morocco. Med Vet Entomol. 1998;12:255-66

32. Baylis $M$, Meiswinkel $R$, Venter GJ. A preliminary attempt to use climate data and satellite imagery to model the abundance and distribution of Culicoides imicola (Diptera: Ceratopogonidae) in southern Africa. J S Afr Vet Assoc. 1999:70:80-9.

33. Baylis $M$, Rawlings P. Modelling the distribution and abundance of Culicoides imicola in Morocco and Iberia using climatic data and satellite imagery. Arch Virol Suppl. 1998;14:137-53.

34. Conte A, Goffredo M, Ippoliti C, Meiswinkel R. Influence of biotic and abiotic factors on the distribution and abundance of Culicoides imicola and the Obsoletus Complex in Italy. Vet Parasitol. 2007;150:333-44.

35. Ippoliti C, Gilbert M, Vanhuysse S, Goffredo M, Satta G, Wolff E, Conte A. Can landscape metrics help determine the Culicoides imicola distribution in Italy? Geospat Health. 2013:8:267-77.

36. Purse BV, Falconer D, Sullivan MJ, Carpenter S, Mellor PS, Piertney SB, et al Impacts of climate, host and landscape factors on Culicoides species in Scotland. Med Vet Entomol. 2011;26:168-77. 
37. Rigot T, Conte A, Goffredo M, Ducheyne E, Hendrickx G, Gilbert M Predicting the spatio-temporal distribution of Culicoides imicola in Sardinia using a discrete-time population model. Parasit Vectors. 2012;5:270.

38. R Core Team. R: A language and environment of statistical computing. Vienna: R Foundation for Statistical Computing; 2012. https://www.R-project.org.

39. Becker RA, Allan RW, Brownrigg R, Minka PT, Deckmyn A. maps: Draw Geographical Maps. R package version 3.2.0. 2017. https://CRAN.Rproject.org/package=maps.

40. Becker RA, Allan RW, Brownrigg R. mapdata: Extra Map Databases. R package version 2.2-6. 2016. https://CRAN.R-project.org/package=mapdata

41. Bivand R, Lewin-Koh N. maptools: Tools for Reading and Handling Spatial Objects. R package version 0.9-2. 2017. https://CRAN.R-project.org/package= maptools.

42. Hijmans RJ. raster: Geographic Data Analysis and Modeling. R package version 2.6-7. 2017. https://CRAN.R-project.org/package=raster.

43. Bivand R, Keitt T, Rowlingson B. rgdal: Bindings for the Geospatial Data Abstraction Library. R package version 1.1-10. 2016. https://CRAN.R-project. org/package=rgdal.

44. Pebesma EJ, Bivand RS. Classes and methods for spatial data in R. R news. 2005. https://CRAN.R-project.org/doc/Rnews/.

45. Cressie N. Statistics for spatial data. Revised edition. New York: Wiley; 1993.

46. McCullagh P, Nelder J. Generalized linear models. London: Chapman \& Hall; 1989.

47. Mullay J. Specifications and testing of some modified count data model. J Econ. 1986;33:341-65.

48. Zuur AF, leno EN, Walker NJ, Saveliev AA, Smith GM. Mixed effects models and extensions in ecology with R. Statistics for Biology and Health. New York: Springer; 2009

49. Breiman L. Random forests. Mach Learn. 2001;45:5-32.

50. Liaw A, Wiener M. Classification and regression by randomForest. R News. 2002;2:18-22.

51. Rowlingson B, Diggle P. splancs: Spatial and Space-Time Point Pattern Analysis. R package version 2.01-40. 2017. https://CRAN.R-project.org/ package $=$ splancs.

52. Pebesma EJ. Multivariable geostatistics in S: the gstat package. Comput Geosci. 2004;30:683-91.

53. Boorman J, Dipeolu OO. A taxonomic study of adult Nigerian Culicoides Latreille (Diptera: Ceratopogoaidae) species. Occ Publ Ent Soc Nigeria. 1979; 22:1-121.

54. Carter HF. New West African Ceratopogoninae. Ann Trop Med Parasitol. 1919;12:289-300.

55. Meiswinkel R, Paweska JT. Evidence for a new field Culicoides vector of African horse sickness in South Africa. Prev Vet Med. 2003;60:243-53.

56. Oem JK, Chung JY, Kwon MS, Kim TK, Lee TU, Bae YC. Abundance of biting midge species (Diptera: Ceratopogonidae, Culicoides spp.) on cattle farms in Korea. J Vet Sci. 2013;14:91-4

57. Yanase T, Matsumoto Y, Matsumori Y, Aizawa M, Hirata M, Kato T, et al. Molecular identification of field-collected Culicoides larvae in the southern part of Japan. J Med Entomol. 2013;50:1105-10.

58. Baylis M, Parkin H, Kreppel K, Carpenter S, Mellor PS, Mclntyre KM. Evaluation of housing as a means to protect cattle from Culicoides biting midges, the vectors of bluetongue virus. Med Vet Entomol. 2010;24:38-45.

59. Garcia-Saenz A, McCarter P, Baylis M. The influence of host number on the attraction of biting midges, Culicoides spp. to light traps. Med Vet Entomol. 2010;25:113-5.

60. Kluiters G, Sugden D, Guis H, Marie Mclntyre K, Labuschagne K, Vilar MJ, Baylis M. Modelling the spatial distribution of Culicoides biting midges at the local scale. J Appl Ecol. 2013;50:232-42.

61. Fall M, Fall AG, Seck MT, Bouyer J, Diarra M, Lancelot $R$, et al. Host preferences and circadian rhythm of Culicoides (Diptera: Ceratopogonidae), vectors of African horse sickness and bluetongue viruses in Senegal. Acta Trop. 2015;149:239-45.

62. Calvete C, Estrada R, Miranda MA, Borras D, Calvo JH, Lucientes J. Ecological correlates of bluetongue virus in Spain: predicted spatial occurrence and its relationship with the observed abundance of the potential Culicoides spp. vector. Vet J. 2009;182:235-43.

63. Rogers DJ, Randolph SE. Mortality rates and population density of tsetse flies correlated with satellite imagery. Nature. 1991;351:739-41.

64. Narasimha Rao PV, Venkataratnam L, Krishna Rao PV, Ramana KV, Singarao MN. Relation between root zone soil moisture and normalized difference vegetation index of vegetated fields. Int J Remote Sens. 1993;14:441-9.
65. Meiswinkel R. Afrotropical Culicoides: C (Avaritia) miombo sp. nov., a widespread species closely allied to C. (A.) imicola Kieffer, 1913 (Diptera: Ceratopogonidae). Onderstepoort J Vet Res. 1991;58:155-70.

66. Eksteen S, Breetzke GD. Predicting the abundance of African horse sickness vectors in South Africa using GIS and artificial neural networks. S Afr J Sci. 2011;107:20-8.

67. Meiswinkel R, Braack LEO. African horse sickness epidemiology: five species of Culicoides (Diptera: Ceratopogonidae) collected live behind the ears and at the dung of the African elephant in the Kruger National Park, South Africa. Onderstepoort J Vet Res. 1994;61:155-70.

68. Meiswinkel R. Afrotropical Culicoides: a redescription of C. (Avaritia) imicola Kieffer, 1913 (Diptera: Ceratopogonidae) with description of the closely allied C. (A.) bolitinos sp. nov. reared from the dung of the African buffalo, blue wildebeest and cattle in South Africa. Onderstepoort J Vet Res. 1989; 56:23-39.

Ready to submit your research? Choose BMC and benefit from

- fast, convenient online submission

- thorough peer review by experienced researchers in your field

- rapid publication on acceptance

- support for research data, including large and complex data types

- gold Open Access which fosters wider collaboration and increased citations

- maximum visibility for your research: over $100 \mathrm{M}$ website views per year

At BMC, research is always in progress.

Learn more biomedcentral.com/submissions 